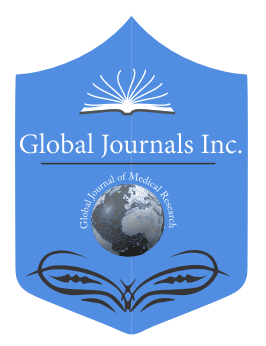

\title{
Detection of Intron22 Mutations in Iraqi Female Carriers in Wasit Province with Hemophilia A
}

\author{
By Maysoon Mohammed Hassan
}

Wasit University

Abstract- The background: One of the prevalent main concerns in the medical world is the identification of Intron22 mutations in the Factor VIII gene carried by Iraqi patient in Wasit town, in Iraq suffering Hemophilia A (classical hemophilia) which is related to a X-chromosome recessive haemorrhage afflictions as the result of a flaw in the coagulation factor VIII (FVIII). It is essentially related with F8 mutations of Intron22 inversion which forms the most typical kind of mutations of blood afflictions worldwide involving half the patients suffering from severe Hemophilia $A$ that possesses mutations, in addition to Intron 1 inversion suffered by $5 \%$ of severe Hemophilia A patients. All of the inversion mutations are suffered mainly by males, and uncommonly by females due to the intrachromosomal recombination among the homologous areas, in inversion 1 or 22, with extragenic copy posited the telomeric to the Factor VIII gene. Unfortunately, there is an absence in Iraq on researches pertaining blood affliction gene identification in persons who carries the Intron22 mutations exception in the current research.

Aims of study: The objectives of the research is to to analyze through the detection mechanisms, the existence of Intron 22 mutations in the Factor VIII gene of 10 Hemophilia A Iraqi carriers cohort families. The hypothesis and anticipated result is that there will be a minimal margin of hazardous possibility for the recurrence. The hereditary F8 mutation is unknown to be present on the maternal side of the patient sufferer due to the possibilty of germline mosaics that exists within the community.

Keywords: Hemophilia A, Factor 8 gene, Carriers, Intron 22 mutations.

GJMR-F Classification: NLMC Code: WH 325

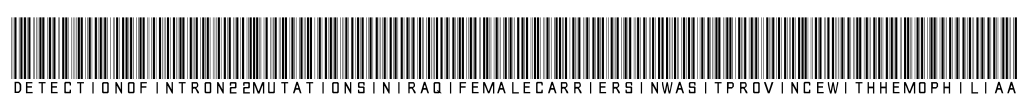

Strictly as per the compliance and regulations of:

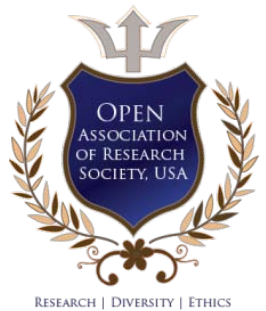

(C) 2017. Maysoon Mohammed Hassan. This is a research/review paper, distributed under the terms of the Creative Commons Attribution-Noncommercial 3.0 Unported License http://creativecommons.org/licenses/by-nc/3.0/), permitting all non-commercial use, distribution, and reproduction in any medium, provided the original work is properly cited. 


\title{
Detection of Intron22 Mutations in Iraqi Female Carriers in Wasit Province with Hemophilia A
}

\author{
Maysoon Mohammed Hassan
}

\begin{abstract}
The background: One of the prevalent main concerns in the medical world is the identification of Intron22 mutations in the Factor VIII gene carried by Iraqi patient in Wasit town, in Iraq suffering Hemophilia A (classical hemophilia) which is related to a X-chromosome recessive haemorrhage afflictions as the result of a flaw in the coagulation factor VIII (FVIII). It is essentially related with F8 mutations of Intron22 inversion which forms the most typical kind of mutations of blood afflictions worldwide involving half the patients suffering from severe Hemophilia $A$ that possesses mutations, in addition to Intron 1 inversion suffered by $5 \%$ of severe Hemophilia $A$ patients. All of the inversion mutations are suffered mainly by males, and uncommonly by females due to the intrachromosomal recombination among the homologous areas, in inversion 1 or 22 , with extragenic copy posited the telomeric to the Factor VIII gene. Unfortunately, there is an absence in Iraq on researches pertaining blood affliction gene identification in persons who carries the Intron22 mutations exception in the current research.
\end{abstract}

Aims of study: The objectives of the research is to to analyze through the detection mechanisms, the existence of Intron 22 mutations in the Factor VIII gene of 10 Hemophilia A Iraqi carriers cohort families. The hypothesis and anticipated result is that there will be a minimal margin of hazardous possibility for the recurrence. The hereditary F8 mutation is unknown to be present on the maternal side of the patient sufferer due to the possibilty of germline mosaics that exists within the community.

Patients and Methods: The current research involved 10 Iraqi Hemophilia A carrier, and 5 healthy sampling to act as the control. This study had utilized medicine and science school labs, with the inclusion of AL Karama Teaching Hospital over a time period from November, 2016 up to January, 2017. The aforementioned respective carriers have a previous history of diagnosed case history and DNA testing.

Results: During the whole of the screening duration for Inv22 (intron twenty two inversions) amongst the Hemophilia A carriers, the outcomes indicated that 4 out of the 10 carriers (40\%) suffer from these mutations.

Discussion: The research findings highlights on the significance of the Inv22 analysis and their relationship with positive hereditary case history within the Hemophilia A carriers, in addition to our ongoing pursuit of seeking for Inv1 mutations.

Conclusions: The outcomes defines the detrimental influence of a diagnosed positive family case history and the proximal affinity lineage in marriage. There is a dire necessity

Author: (MSc). Zoology-Biotechnic-Genetic, Department of Biology, College of Dentistry, Researcher in Medicine college, Research Laboratory-Wasit University. e-mail: mayalsaraf@gmail.com for Hemophilia A carriers to be given specialized and dedicated obstetrical attention with close contact with the haemophilia centre, in addition the management processes concerning the case should be available ought and identified.

The outcome manifests the pathway towards a genetic guideline. Having the information pertaining the gender of the foetus gender is significantly crucial to assist in the supervision of labor, in addition to diagnostic processes.

Keywords: Hemophilia A, Factor 8 gene, Carriers, Intron 22 mutations.

\section{INTRODUCTION}

I ereditary haemorrhage afflictions are specifically challenging and impacts on the majority of ladies and young females due to the monthly discharge of menses, thus impacting on the wellbeing of the reproductive system(1). On another note, males globally are susceptible to be sufferers of Hemophilia $A(H A)$ due to the hereditary $X$-chromosome related to haemorrhage afflictions, in the majority part is related to Factor VIII gene mutations, which leads to the inadequacy of clotting Factor VIII (FVIII) which plays a significant role in hemostatic system (2). This condition inflicts one per 5,000 males globally. The natality incidences worldwide is homologous regardless of ethnicity, perhaps due to the great impetuous degree of mutation in F8 and its presence situated on the $X$ chromo-some(3). Hemophilia $A(H A)$ is manifested in a limited diverse range of clinical acuteness, with the respective diversity which are parallel to the type and locus of the induced genetic flaw (4:5). Hence, Hemophilia $A$ is the result of a heterogeneous range of flaws that occur at the molecular level in Factor VIII alongside the elisions, huge intron inversions, nonsense mutations, ins/del-frame shifts, splice variants, in addition to an extensive scope of missense point mutations. The aforementioned elements have the possibility to result in flaws within the expression, secretion, and/or half-life of Factor 8 in the flow (6).

The identification of the carrier and symptomatic process might be delivered straight through the evaluation on the diverse ascertained mutations or evasively according to case (lineage) history through analyzing the relationship (7).

The remnant functioning of plasmatic Factor 8 in heterozygous carrier females of severe F8 mutations is identified as a non-dominant X-linked disorder, which is typically found at fifty percent of a person who is not a carrier. Although extremely uncommon, homozy- 
gous females who were offsprings of afflicted paternal parent, in cases of marriages with close next-of-kin have a higher potential to be inflicted with blood disorder (Hemophilia) in a likewise situation to hemizygous male patients, and alternatively in Turner Syndrome cases $\left(45, X^{\wedge}\right)$ (8). Nevertheless, typical hemophilia (blood disorder) cases of expression in females are caused by the presence of biased Lyonization (biased $X$ chromosome inactivation), in addition to the heterozygous carrier situation (Morris syndrome, 46, XY) (9).

A majority of female are commonly asymptomatic, nonetheless, females have the possibility to be symptomatic (10). According to Haldane's formula (Haldane, 1935) it is anticipated that one-sixth of hemophilia genes are dominant in each generation. Hemophilia A, hence, manifest an extremely great level of mutational heterogeneity which conceals the carrier and prenatal diagnoses which are essential for genetic advisory (11).

The Factor VIII gene embed the code plasma protein VIII, a huge plasma glycoprotein that operates in the clotting cascade, being a cofactor for the factor IXadependent that activates the factor $X(12)$. The Factor 8 gene consists of 26 exons, that has a wide diversity from 69 to 3,106 base pairs (bp), with 25 introns encompassing the range of $186-\mathrm{kb}$ genomic DNA, which are plotted to the remote end of X-chromosome (Xq28) long arm. Intron arrangement order is $177.9 \mathrm{~kb}$, and are separated from the initial transcript product through the entire splicing towards the generation of a mature Factor VIII mRNA of approximately 9 kilobytes in length which exhibits a precursor protein containing 2,351 amino acids.

From the more extensive intron arrangement orders, there is an inclination to discover six which is more extensive than fourteen kilobyte (introns-1, 6, 13, 14, 22 and 25), having intron 22 being largest at 32.8 kilobyte in terms of length (13), with Intron twenty two inversion (Inv22) entailing the typical public type in approximately forty to forty-five percent of acute hemophiliacs, in addition from two up to five percent of acute Hemophilia $A$ incidences are full of Intron one inversion (Inv1) (14:15).

According to the work by Rossiteret al. (1994), they discovered that Inv22 stemmed largely and significantly from the male germ cells. They conjectured the existence of another $X$ chromo-some in female meiosis could inhibit the intrachromosomal non-allelic pair-ing required for Intron twenty two inversion (16). Every individual inversions is the resultant from the nonallelic meiotic intrachromosomal recombination among the int22h-1 region within the Factor VIII site, with either int22h-2 or int22h-3, within the male germ cells (16). Int22h-1 recombines with the ultimate telomeric duplicate which is normally is mutually inclined to int22h1 , and commonly it entails int22h-3. The aforementioned int22h-1/int22h-3 recombination results in the inv22 sort I. Furthermore, a minority of incidences, the inversion was disclosed to be caused by the two recombination occurences. The beginning stage involved a recombination between the arms of the palindrome inv22h-2/ inv22h-3, which was identified as a public nondeleterious inversion polymorphism. The event altered the locations and inclinations of int22h-2 and located it at the optimal telomeric and inverse location to inv22h-1. The next recombination between inv22h-1 and inv22h-2 terminates in inv22 sort II (17). Moreover, the recombination among the int22h-1 with the equally leaning duplicate of either int22h, int22h-2 or int22h-3 is anticipated to be the cause for huge harmful deletions (Del22), in addition to the possible non-deleterious duplications (Dup22), in contrast with the typical inversions (18). The inversions that occur in individuals with two distal or two proximal estrogenic duplicates are known as type3 inversions (19).

The serial arrangement order of the human $X$ chromosome manifests the int22h-2 and int22h-1 to have an exact positioning, meanwhile the int22h-3 is located at the opposite position to them; where int22h-2 and int22h-3 are part of defective palindrome possessing a central single loop of 67,3 kilobytes, with arms of $50,5 \mathrm{~kb}(20)$. The recombination involving the int $1 \mathrm{~h}-1$ and int1h-2 copies from sister chromatids or homologous chromatids with the chromosomes, would result in dicentric chromosomes and acentric portions. Thus, it would not result in potential embryos. The inv1 and inv22 inhibited the construction of a complete length of the Factor VIII messenger RNA (mRNA), and terminates in the inadequate Factor VIII proteins causing acute $\mathrm{HA})(21: 14)$.

Based on the latest to proof, intron22 segregates the exons 22 and 23 (IVS22) consisting of the incidences of a bidirectional (CpG island) which initiates the transcription of a duo of expressed genes (nested genes, F8A and F8B). It is a part of an extensive GC sequence of 9.5 kilobytes (int22h-1) which recur at two locations oriented at the the Xqtelomere (int22h-2 and int22h-3)(20). According to the the opinion of Youssoufian et al. (1986), the statements showed that CpG dinucleotides areal areas of mutation. It was conjectured that methylated cytosines is equally critical areas for mutations caused by 5-methylcytosine will spontaneously deaminize to thymine, resulting in a C-toT transition in DNA (22). This CpG island was associated to a 1.8 kilobyte transcript elevated to $A$ gene (F8A). The nested Factor VIII associated A gene was positioned in an opposite orientation to that of Factor VIII, comprising of non-intervening arrangements $(23 ; 24)$. From the work by Freije and Schlessinger (1992), the subsequently indicated that the $\mathrm{X}$-chromosome comprises three replications of Factor $8 \mathrm{~A}$ and its adjacent areas, one in intron 22 and two telomeric and approximately five 
hundred kilobyte up the F8 gene transcription initiation site(25).

Meanwhile the F8B transcription of $2.5 \mathrm{~kb}$ originates from identical $\mathrm{F} 8$ intron $22 \mathrm{CpG}$ island, due to the F8A and transcribes in the same orientation as F8. The $\mathrm{CpG}$ island functions to encourage bidirectional acts for the F8A and F8B genes, which are jointly manifested universally all over in diverse tissues.

The varying F8A and F8B transcripts initiates from within the 122 bases of each starting point(24).

The codification of a forty $\mathrm{kD}$ huntingtin-linked protein was indicated to originate from the F8A gene, known as HAP40 and is assumed to be related inside the abnormal nuclear local positioning of the hunting-tin protein in Huntington ailment(26). From the study by Lakich et al. (1993), they disclosed the rare occurrence of intron 22 in many ways. Comprising $32.8 \mathrm{~kb}$, it is the most expansive intron in the Factor VIII gene. The two mutations that resulted in diseases and neutral polymorphisms appear renewed in each new generation. In the case of a world population of 7 -10^ 9 people and a mean mutation frequency of 10-8 for each base pair and generation. It is obvious that entire transformations associated with life will undergo mutation recurrence once(27).

The mutation (intron 22 inversion) happen approximately $4 \times 10^{-6}$ for each gene, for each gamete, and for each generation $(15,28)$. (29). Inv22-positive patients manifest heightened potential towards the hazard of raising the inhibitors in comparison with patients resonating alternative acute mutations (30).

\section{The Aims of Study}

The objective of the current study is to identify the presence of intron 22 mutations in the non-coding FVIII gene of 10 gender-associated afflictions (hemophilic) Iraqi carrier kinship group by Polymerase Chain Reaction (PCR) through Multigene Optimax (Thermo Cycler) device, in addition to and direct sequencing in analyzing inversion. Intron 22 primer with 1916 base pairs generations indicated in figures no.(1),(2),(3) through the utilization of various differing programs for the mutations analysis that consist of NTI vector Pro., Clustal W technique of MEGA4 pro., NCBI/ BIAST program, Chromos Pro, Mutation Surveyor.

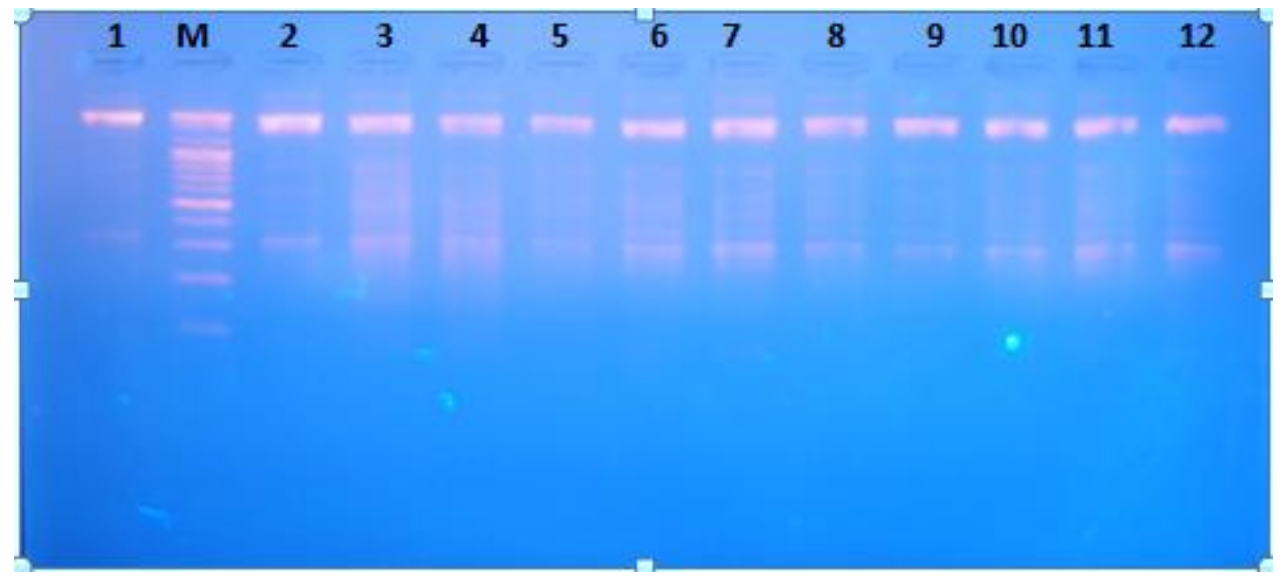

Figure 1: PCR products of FVIII gene on $2 \%$ agarose gel at 70 voltages for one hour. Intron22.

Lane 1T: Lane-M-standard molecular weights: Lane 2, 3, 4, 5, 6, 7, 8, 9, 10, C, 11: Lane 12T. Gel was stained with Ethidium bromide staining. ${ }^{\star} \mathrm{C}$ for carriers; $T$ for control 


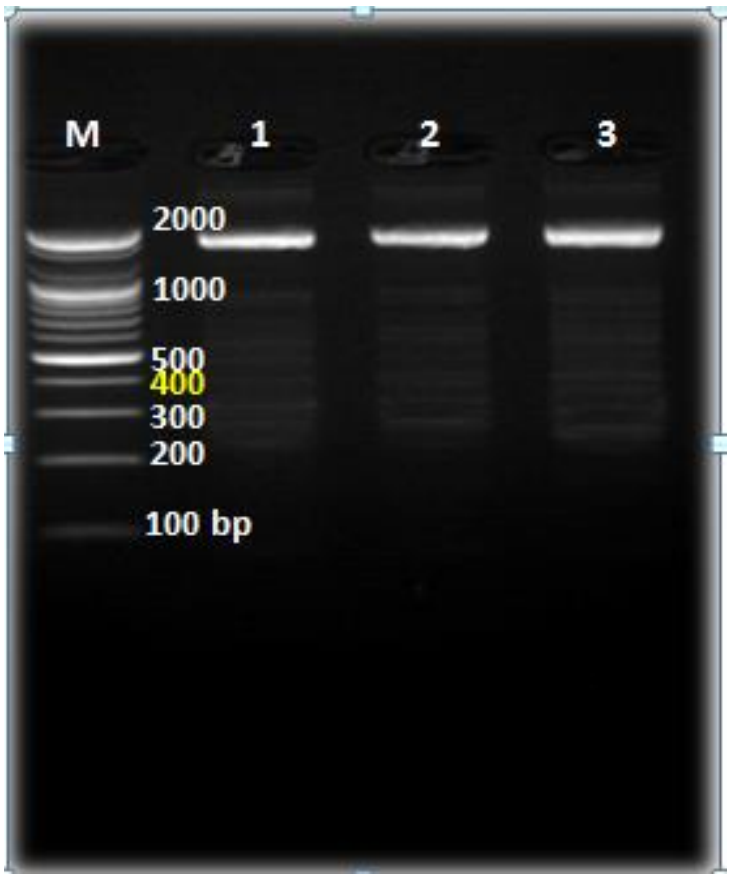

Figure 2: PCR products of FVIII gene on $2 \%$ agarose gel at 70 voltages for one hour. Intron22. Lane-M-standard molecular weights: Lane 1T: Lane 2, 3, C. Gel was stained with Ethidium bromide staining. ${ }^{*} \mathrm{C}$ for carriers; $T$ for control

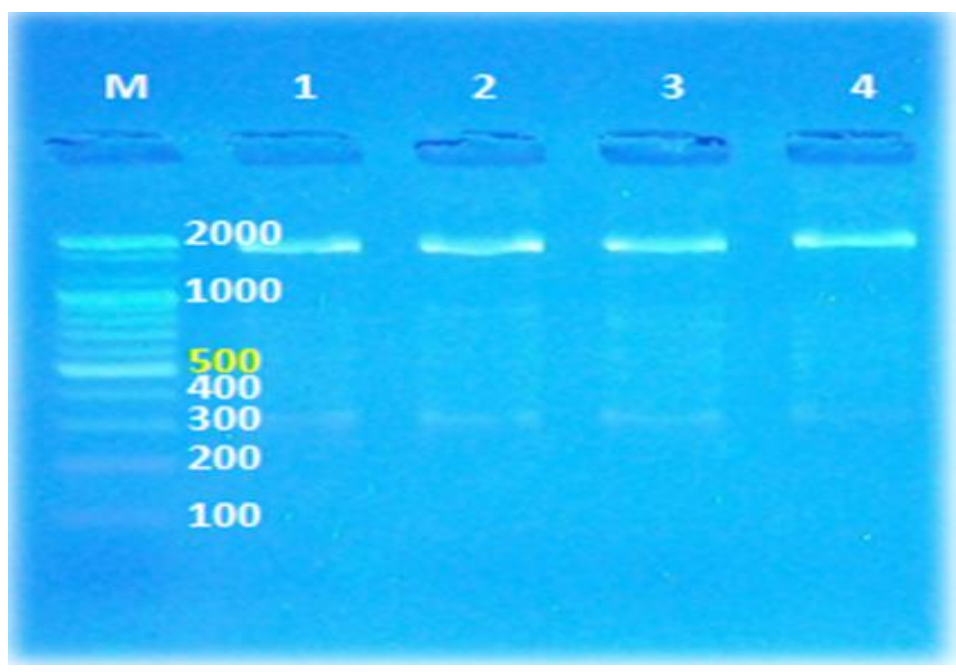

Figure 3: PCR products of FVIII gene on $2 \%$ agarose gel at 70 voltages for one hour.

Intron22 - Lane-M-standard molecular weights: Lane 1T: Lane 2, 3, C. Gel was stained with SYBER Green staining. ${ }^{*} \mathrm{C}$ for carriers; $T$ for control.

\section{Collection of samples}

This study has enclosed ten Iraqi carriers with classical hemophilia (hemophilia A) from unrelated families and five healthy members as control, were collected from Al-Karama teaching hospital, in Wasit province- kut-city. The age of carriers were ranged from twenty four to sixty four year.

\section{ili. Methods}

All samples study of hemophilia A completed in medicine, science college and of AL-Karama Teaching
Hospital laboratories .These carriers formerly identified based on family history, DNA testing. and a few information like age, sex, relative state. After checking the extracted DNA for its purity and concentration, its being subjected to amplification to choose area of $F$ VIII, which has intron 22 then Sequencing has being Conducted for intron22 for all carriers and control for molecular analysis that detection of mutation of commonest segment of FVIII gene. Figure (4) shown PCR product of intron 22 for carrier sand control. 


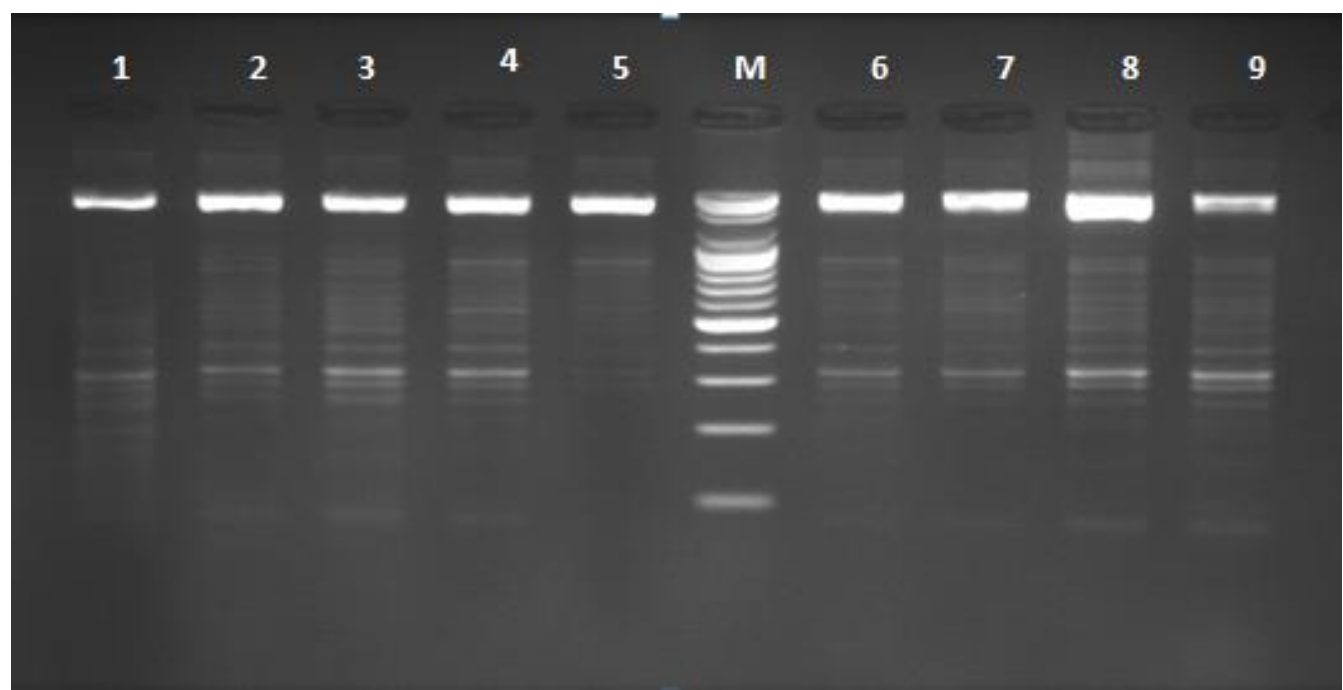

Figure 4: PCR products of FVIII gene on $2 \%$ agarose gel at 70 voltages for one hour.Intron22

Lane 1, 2, 3, 4, 5 C: Lane-M-standard molecular weights: Lane 6, 7, 8, 9 T. Gel was stained with Ethidiumbromide staining. ${ }^{*} \mathrm{C}$ for carriers; $T$ for control.

\section{iv. Carrier Detection}

Approximately 10 percent of females with one F8 pathogenic variant and one normal allele have a factor VIII clotting activity under than thirty percent a bleeding disorder; mild bleeding can take place in carriers with low-normal coagulation factor 8activity (38).

In this study all carrier females are asymptotic because of the lyonization phenomenon and FVIII activity is over fifty percent that genetic defects are known by family history assess men $(39 ; 40)$.

Carrier testing by molecular genetic testing is feasible for utmost at-risk females if the pathogenic variant has been known within the family. Factor VIII clotting activity, or its ratio to von Willebr and factor level, isn't a reliable check for determinant carrier status: it will solely be suggestive if low, because factor VIII coagulation activity in plasma is augmented with pregnancy, aerobics exercise, oral contraceptive use, and chronic inflammation. factor VIII coagulation activity in plasma is just about twenty five percent lower in people of blood group $O$ than in people of blood groups $A, B$, or $A B$ and therefore the majority of obligate carriers, even of severe hemophilia $A$, have normal factor VIII clotting activities.

\section{Results}

\section{a) DNA Isolation}

The genomic DNA extracted from blood of Hemophilia A patients showed good single band when fractionated by gel electrophoresis as show in figure no. (5) then checked for their purity and by using spectrophotometer device.

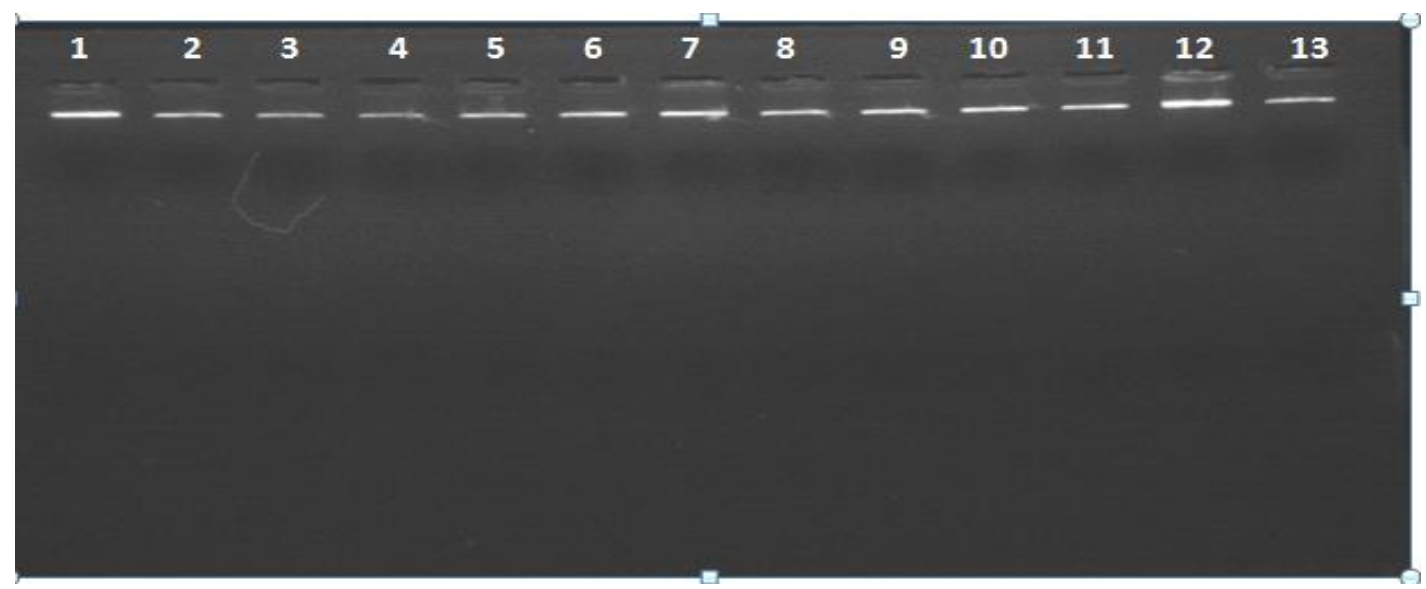

Figure 5: Chromosomal DNA electrophoresis showing bands on $2 \%$ agarose gel at 70 volt/ $\mathrm{cm} 2$ for 1 hour.

Lane (1) -C,Lane 2 C, Lane 3 C, Lane 4 $\neg \neg$ C, Lane 5 C, Lane 6 C, Lane 7 C, Lane 8 C, Lane 9 C, Lane 10 C, Lane 11 , Lane 12 $\mathrm{T}$, Lane $13 \mathrm{~T}$. Gel was stained with Ethidium bromide staining and using loading dye.

${ }^{*} \mathrm{C}$ for carriers; $T$ for control 


\section{b) DNA sequence analysis}

Sequencing has being run for all the exons and intron 22 for all patients and control for process of determining the exact order of nucleotides within a DNA molecule. It includes any method or technology that is used to determine the order of the four bases (adenine, guanine, cytosine, and thymine) in a strand of DNA. The analysis of nucleotide sequencing was done by using $\mathrm{NCBI} /$ Blast computer program, Nucleotide sequences were translated into amino acid sequences also by using the Blast program. Each DNA sequence obtained was aligned with reference $F$ VIII gene sequence that means reference Genomic DNA for intron22 then, same sequence being aligned with Mutation Surveyor software to check the normal variation and checking amino acid change.

The study was done for 10 hemophiliac carriers (mothers), and 5 control samples, to detect intron 22 inversion which responsible for hemophilia disease. All control samples were obtained from female gender. We found Inv22 mutations in 4 from 10 carriers. During the screening for Inv22 mutations among the HA carriers and controls, , we did not found this mutation or gene abnormality in all controls. family history and consanguinity state of haemophilia was recorded in some carriers. Percentage of Hemophiliac carriers group data is depicted in (Table1).

Table 1: Percentage of Hemophiliac Carriers Group Data

\begin{tabular}{|c|c|c|c|c|c|c|c|c|}
\hline $\begin{array}{c}\text { Carriers sample } \\
\text { no. }\end{array}$ & $\begin{array}{l}\text { Mutation } \\
\text { segment }\end{array}$ & \multicolumn{2}{|c|}{ Mutation।Genome } & Mutation type & \multicolumn{2}{|c|}{ Family history } & \multicolumn{2}{|c|}{ Consanguinity state } \\
\hline 1 & Intron 22 & \multicolumn{2}{|c|}{ nill } & - & \multicolumn{2}{|c|}{ negative } & \multicolumn{2}{|c|}{ positive } \\
\hline 2 & Intron 22 & \multicolumn{2}{|c|}{ nill } & - & \multicolumn{2}{|c|}{ negative } & \multicolumn{2}{|c|}{ negative } \\
\hline 3 & Intron 22 & \multicolumn{2}{|c|}{ Inth22 } & Inversion & \multicolumn{2}{|c|}{ negative } & \multicolumn{2}{|c|}{ negative } \\
\hline 4 & Intron 22 & \multicolumn{2}{|c|}{ Inth22 } & Inversion & \multicolumn{2}{|c|}{ positive } & \multicolumn{2}{|c|}{ negative } \\
\hline 5 & Intron 22 & \multicolumn{2}{|c|}{ Inth22 } & Inversion & \multicolumn{2}{|c|}{ positive } & \multicolumn{2}{|c|}{ negative } \\
\hline 6 & Intron 22 & \multicolumn{2}{|c|}{ nill } & & \multicolumn{2}{|c|}{ positive } & \multicolumn{2}{|c|}{ positive } \\
\hline 7 & Intron 22 & \multicolumn{2}{|c|}{ Inth22 } & Inversion & \multicolumn{2}{|c|}{ positive } & \multicolumn{2}{|c|}{ positive } \\
\hline 8 & Intron 22 & \multicolumn{2}{|c|}{ nill } & - & \multicolumn{2}{|c|}{ negative } & \multicolumn{2}{|c|}{ negative } \\
\hline 9 & Intron 22 & \multirow{2}{*}{\multicolumn{2}{|c|}{$\frac{\text { nill }}{\text { nill }}$}} & - & \multirow{2}{*}{\multicolumn{2}{|c|}{$\begin{array}{l}\text { positive } \\
\text { positive }\end{array}$}} & \multirow{2}{*}{\multicolumn{2}{|c|}{ positive }} \\
\hline 10 & Intron 22 & & & - & & & & \\
\hline \multirow{4}{*}{ Total } & & Yes & No & & Positive & Negative & Positive & Negative \\
\hline & & & & & & & & \\
\hline & & 4 & 6 & & \multirow[t]{2}{*}{$60 \%$} & \multirow[t]{2}{*}{$40 \%$} & \multirow[t]{2}{*}{$40 \%$} & \multirow[t]{2}{*}{$60 \%$} \\
\hline & & \multicolumn{2}{|c|}{10} & & & & & \\
\hline
\end{tabular}

Mutations screening conducted throughout the study shows that most common mutations and located in, intron 22.Carrier no.3 appears in this study aligned was regarded as first carrier detect with intron 22 inversion of the FVIII gene reveal with no family history and consanguinity state as showed in figures no $(6,7)$. 


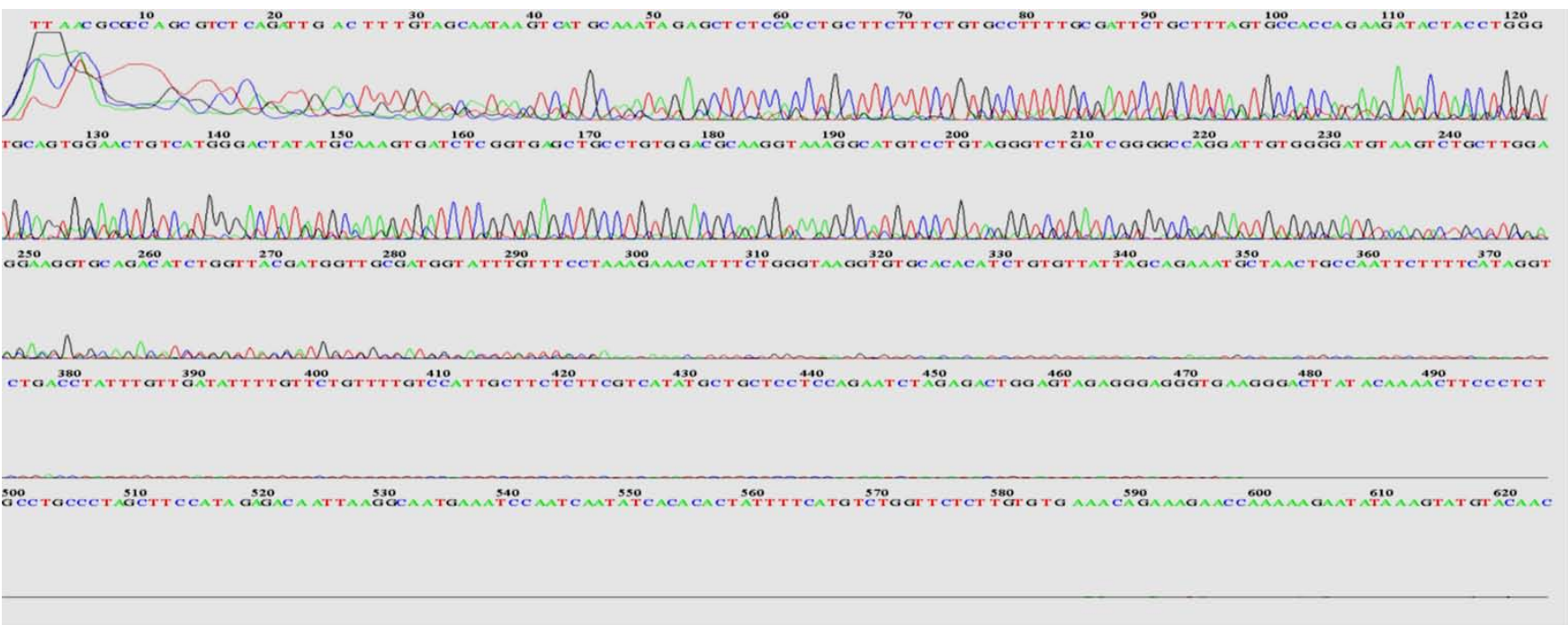

Figure 6: DNA sequencing (forward) for carrier no. 3 detect with Inv22.

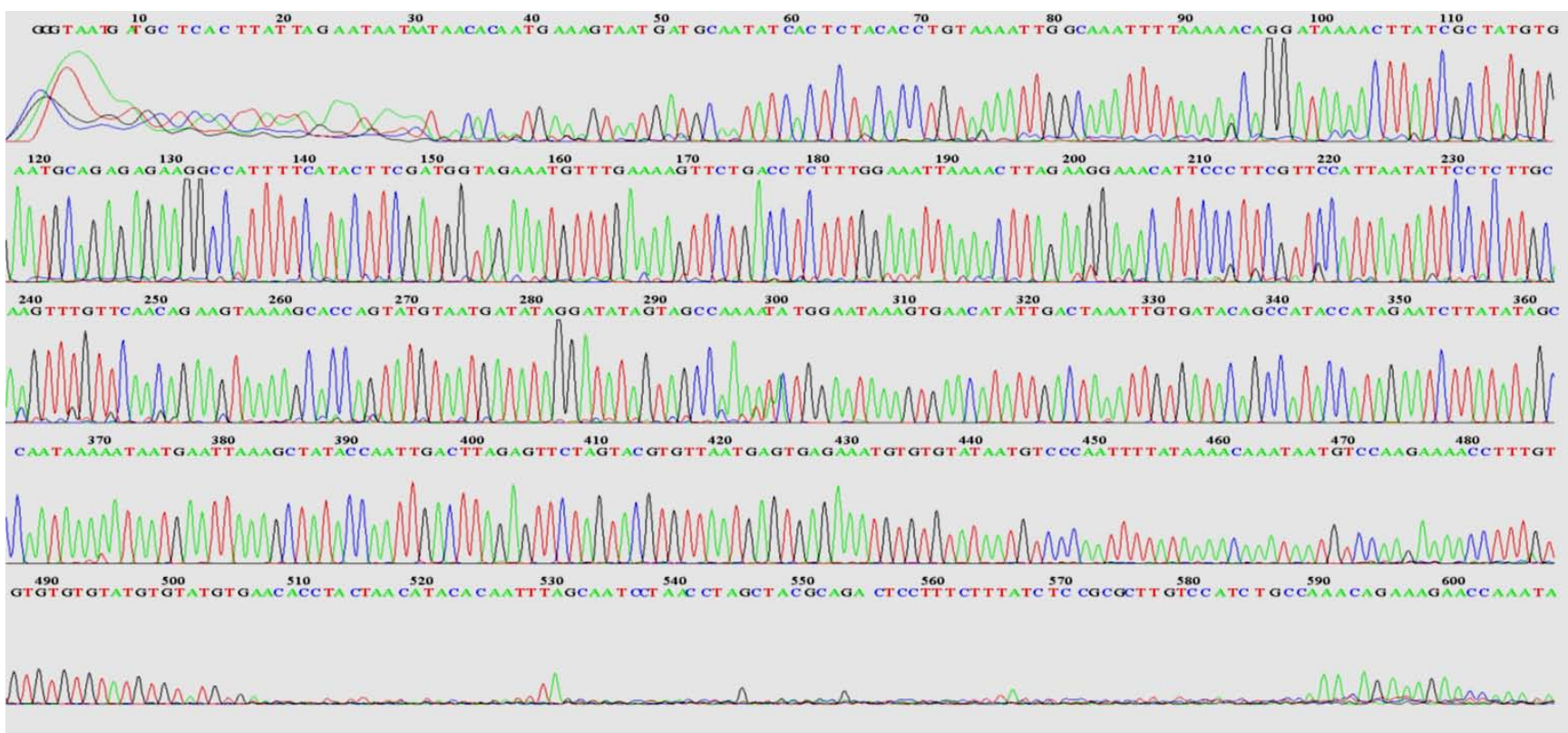

Figure 7: DNA sequencing (reverse) for carrier no. 3 detect with Inv22.

Carrier no.7 appears in this study aligned was regarded as first carrier detect with intron 22 inversion of the FVIII gene reveal with positive family history and consanguinity state as showed in figures no $(8,9)$. 


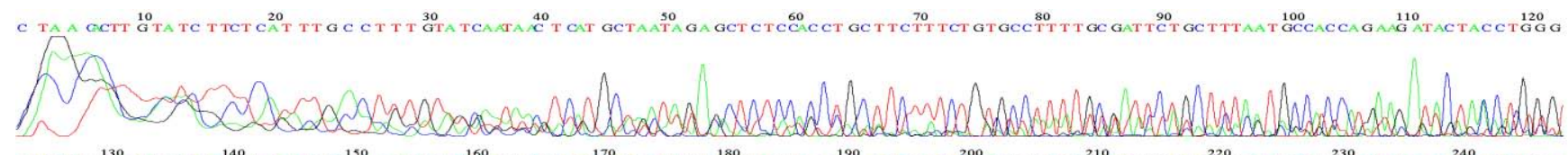

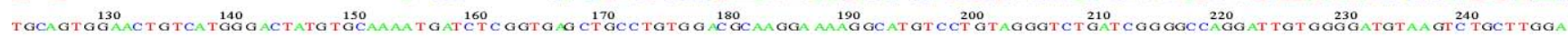

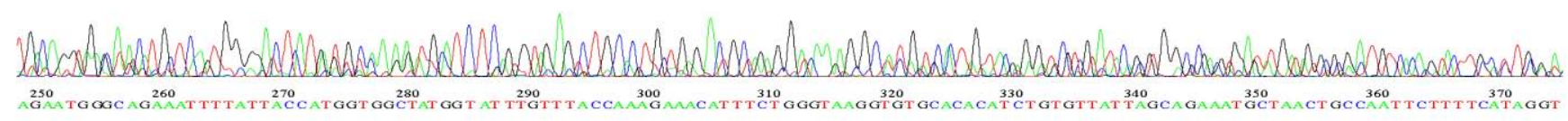

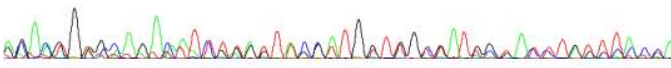

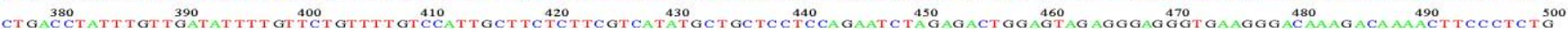

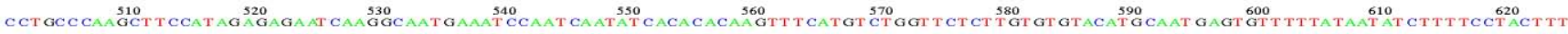

Figure 8: DNA sequencing (forward) for carrier no. 7 detect with Inv22.

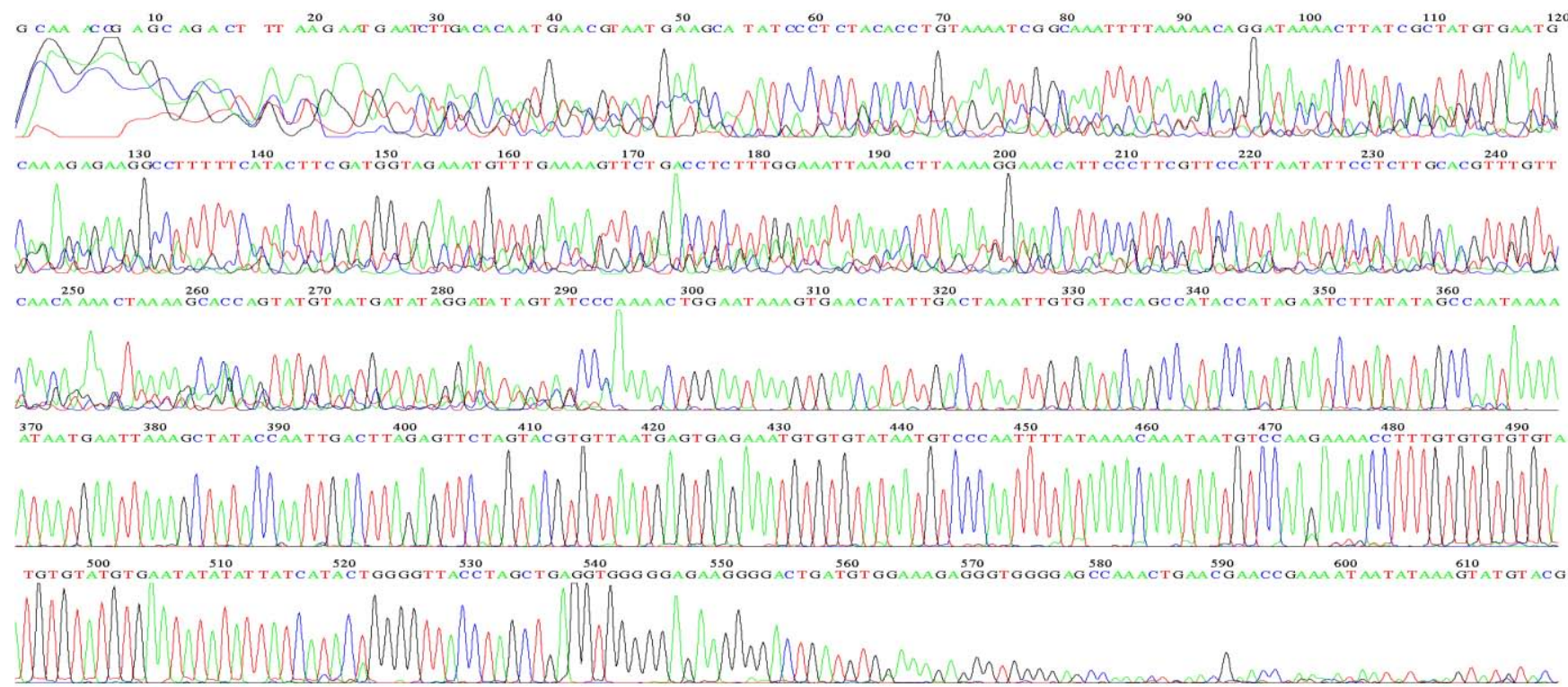

Figure 9: DNA sequencing (reverse) for carrier no. 7 detect with Inv22.

Becker et al. (1996) assessed the male: female ratio of mutation recurrence $(\mathrm{k})$ to be 3.6 . By use of the percentages of mutation origin in maternal grandfather to patients' mother or to maternal grandmother, $\mathrm{k}$ values were directly estimated as 15 and 7.5 , respectively. As each mutation type separately which an inversion of the gene presented a 10-fold-higher mutation rate in male germ cells(31).Although intron 22 segment in the noncoding regions of FVIII gene, intron 22 mutations intermittent the F8 mRNA between exon 22 and23 with large inversion and translocation of nucleotides between these two exons(32).

Inversion of intron 22 (inv22) originates $50 \%$ of cases of severe $\mathrm{HA}$ and is a major risk factor for inhibitor development and The non-significant risk for developing inhibitors among inv22-positive patients agrees with the variety of genetic and non-genetic factors involved in such a complication (30). Other normal changes in genomes (normal variants) not indicated in all carriers VIII gene which all intron 22 involved have been aligned and compared the all possible variants.

\section{Discussion}

The current study examined different properties of mutations carrying F8 haplotypes. This information was used to infer whether same mutations. Carrier females have a 50\% chance of transmitting the F8 pathogenic variant in each pregnancy: sons who inherit the pathogenic variant will be affected; daughters who inherit the pathogenic variant are carriers. Affected 
males transmit the pathogenic variant to all of their daughters and none of their sons.

Intron 22 Mutations Frequency Percentage

In this study, four from ten Iraqi carrier females

from ten unrelated families were had intron 22

mutationas showed in figure (10).

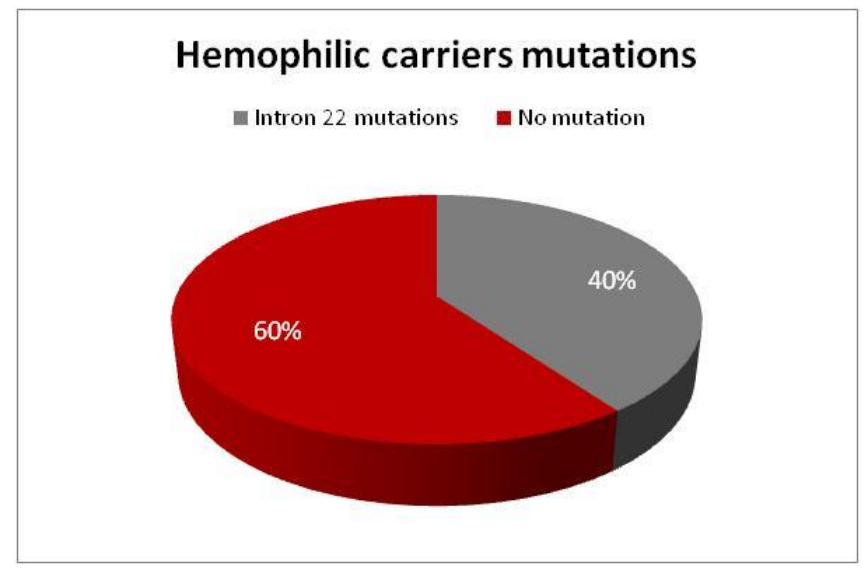

Figure 10: The percentage of intron 22 mutations frequency in hemophiliac carriers (mothers).

The mutation is forecast to impair attachment to the factor VIII (FVIII) carrier protein, von Willebrand factor, and thus increased clearance of FVIII from plasma. Clinical and molecular characterization of these carriers is essential to raise follow-up, genetic counseling and treatment of the disease (33).Increased risk are probable if the F8 pathogenic variant has been identified in a family member or if informative (family history) intragenic linked markers have been recognized which genetic counseling deals with genetic risk valuation and the use of family history and genetic testing to explain genetic status for family members. In this study six from ten carriers are with a hemophilia history (60\%) which 3 from four carriers have (Inv22) mutations with positive family history represents a major factor for genetic predisposition lead to defective FVIII gene. Carrier no.3 appears in this study aligned was regarded as first carrier detect intron 22 inversion of the FVIII gene reveal with no family history and consanguinity state. There are several clarifications for a hemophilic carrier being identify with inv22 when there is no history of hemophilia in the family which about 30 per cent of these cases arise from aspontaneous mutation.

1. The mother is a carrier of a new disease-causing mutation that occurred in one of the following ways:

As a "germ line mutation" (i.e., in the egg or sperm at the time of her conception so the mother is then the first person in the family to transmit hemophilia. Her children might be influenced either as carriers or as hemophiliacs (34). And thus show in every cell of her body and noticeable in her DNA). Ninety-eight percent of mothers of a simple case with an intron 22 inversion are carriers because most of these mutations arise in spermatogenesis.

0 As a somatic mutation (i.e., a alteration that arisen very early in embryogenesis, subsequent in somatic mosaics in which the pathogenic variant is current in some but not all cells and may or may not be obvious in DNA).

(- As germ line mosaics (in which some germ cells have the pathogenic variant and some do not, and in which the pathogenic variant is not evident in DNA from her leukocytes).

2. The mother is a carrier and has inherited the pathogenic variant either from her mother who has a new disease-producing variant or from her asymptomatic father who is mosaic for the pathogenic variant.

3. The mother is a carrier of a pathogenic variant that rose in a previous generation and has been send on through the family without manifesting symptoms in female carriers due to the lionization which hemophilia does certainly run in the family but there is no indication of it because no hemophiliac boys have been born (35:36)

General, the mother has an roughly $80 \%$ chance of being a carrier when her son is the first influenced individual in the family; however, the mother of a severely affected male with an intron 22 inversion has a $98 \%$ chance of being a carrier (37) and about $40 \%$ of carriers (four) under study with consanguinity marriage that one from four carriers have (Inv22) mutations with positive consanguinity marriage result in concentrated the bad gene copy. Figure no. (12) showed DNA sequencing for carrier no.7 detect with intron 22 mutation in factor 8 gene and represent 
positive family history and consanguinity state and Figure no.(11) below showed alignment of hemophilic carrier no.7 detect with intron 22 mutation and control of selected intron 22 sequence with the genomic DNA reference in deep details and represent positive family history and consanguinity state.

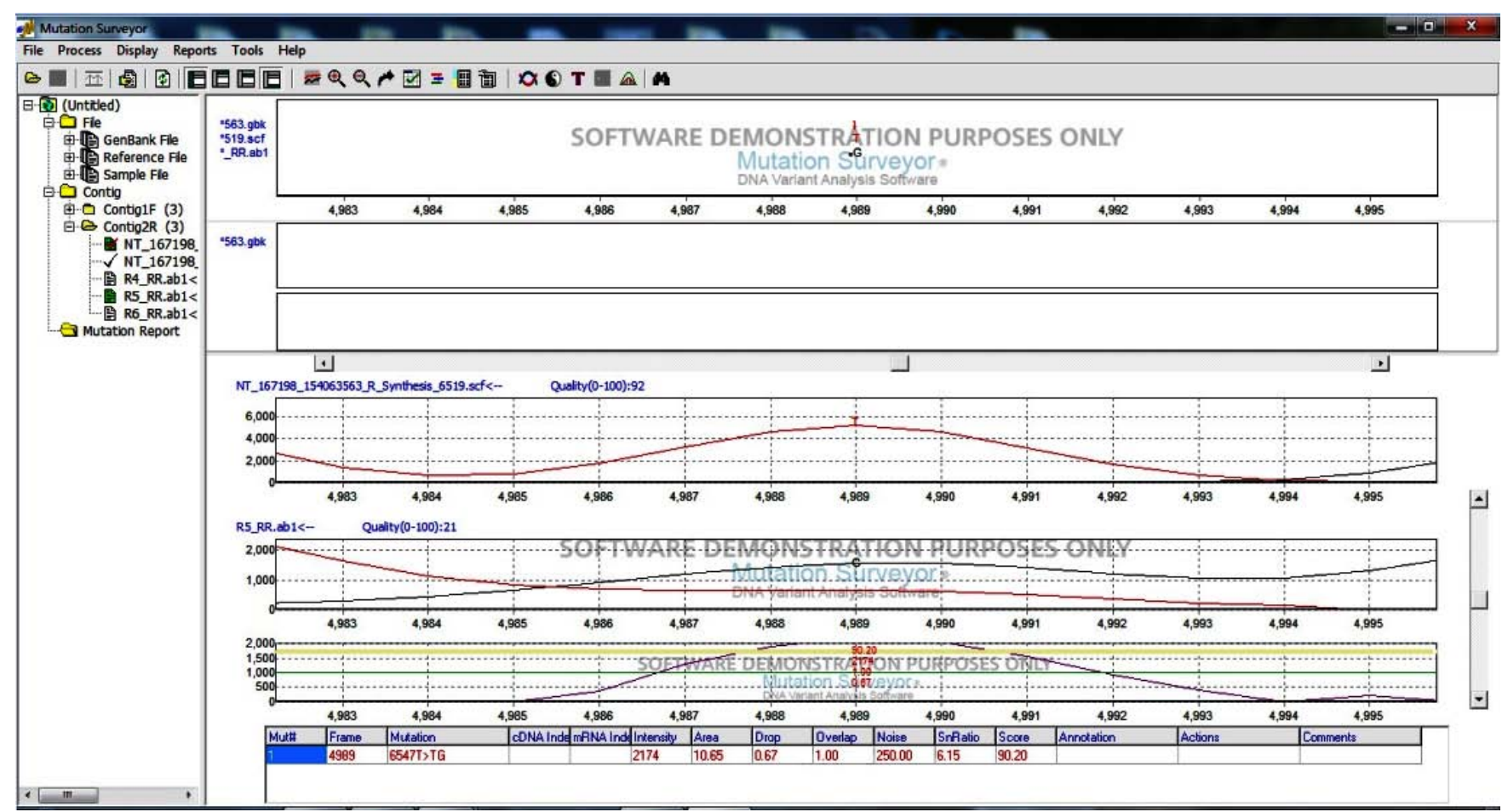

Figure 11: Alignment of hemophilic carrier and control of selected intron 22 sequence with the reference in deep details.

Figure no. (7) Below represents another alignment of hemophilic carrier shown mutations.

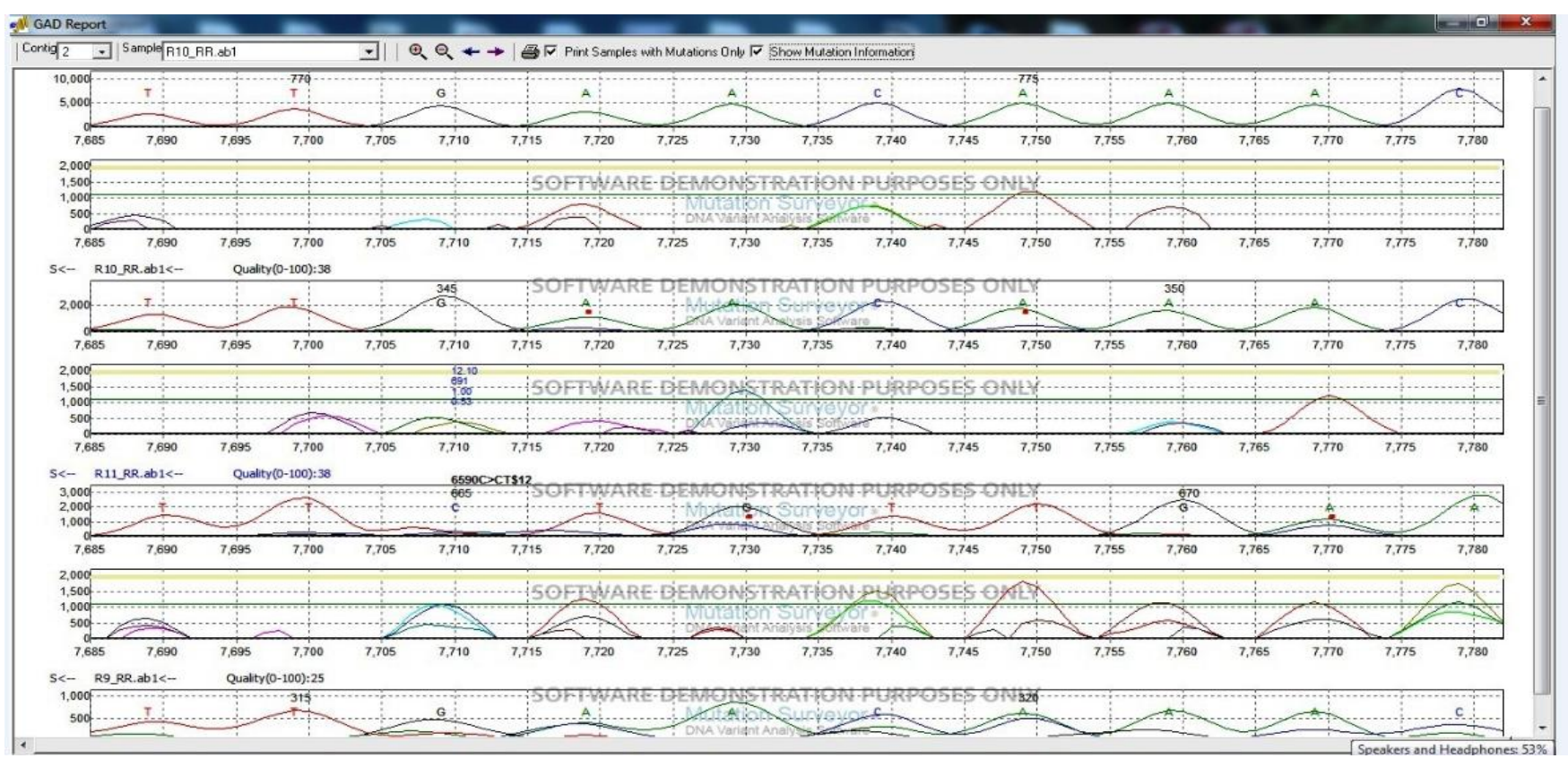

Figure 12: Alignment of hemophilic carrier of selected intron 22 sequence with the reference showing mutations in deep details. 


\section{Vil. Conclusion}

Hence present study indicated that detection of Intron 22 mutations in F8 gene is important in identifying female with genetic defects that leads to the birth sons affected with hemophilia A disease and females almost as carriers. This result represents a step for helpfully guide the direction of molecular study in genetic counseling and subsequent for facilitate management in labour and for prenatal diagnosis also for prevention of the inhibitor development which inversion of intron 22 (inv22) is a major risk factor involved in such a complication. This knowledge represents a step .Most of cases are with a family history $(60 \%)$ represent a major factor for genetic predisposition lead to defective FVIII gene and about $40 \%$ of carriers under study with consanguinity marriage result in concentrated the bad gene copy so this is highly suggestive that hemophilia disease is not uncommon. There is an obvious public ignorance about the role of heredity in many disorders in Wasit province.

\section{References Références Referencias}

1. James, A.H.(2005). More than HMB: a review of the obstetric and gynecological manifestations of bleeding disorders. Hemophilia ; 11:295-307.

2. Salazar-Sánchez L., Jiménez-Cruz G., Mendez M., Chaverri P., Alvarado P., Schröder W, Wulff K., Sandoval M., Herrmann F.H, Pavlova A., Oldenburg J.(2010). Molecular analysis of FVIII gene in severe HA patients of Costa Rica. Hamostaseologie. ; 30 Supple 1:S150-2.

3. Fogarty P.F., Kessler C.M. Hemophilia A and B. In: Kitchens C.S., Kessler C.M., Konkle BA, eds. Consultative Hemostasis and Thrombosis. 3rd ed. Philadelphia, PA: Elsevier Saunders; 2013:45- 59.

4. Bogdanova, N. ; Markoff, A.; Eisert, R.; Wermes, C.; Pollmann, H.; Todorova, A.; Chlystun, M.; NowakGöttlU:; Horst, J. (2007). Spectrum of molecular defects and mutation detection rate in patients with mild and moderate hemophilia A. Human Mutation Journal; 28(1):54-60.

5. Anjali A. Sharathkumar, Manuel Carcao. (2011). Clinical Advances in Hemophilia Management. Pediator Blood Cancer; 57:910-920.

6. Fay, P.J.; (1988). Reconstitution of human factor VIII from isolated subunits. Archives of Biochemistry and Biophysics; 262 (2):525-531.

7. Botton, P.H.; Maggs, K.J.; Hemophilia A and B, Lancet, 2003 24,361(2003).

8. Graw, J.; Brackmann, H. H.; Oldenburg, J.; Schneppenheim, R.; Spannagl M.; Schwaab, R.(2005). Hemophilia A: From mutation analysis to new therapies. Nat. Rev. Genet. 6, 488-501.

9. Kasper, C.K.; Buzin, C.H. Genetics of Hemophilia A and B. An Introduction for Clinicians, 2009, 1st ed.;
Southland Publications: Pasadena, CA, USA, 2009; pp. 27-29.

10. V. R. Byams, P. A. Kouides, R. Kulkarni, J. R. Baker, D. L. Brown, J. C. Gill, A. M. Grant, A. H. James, B. A. Konkle, J. Maahs, M. M. Dumas, S. Mcalister, D. Nance, D. Nugent, C. S. Philipp, J. M. Soucie and E. Stange. (2011).Surveillance of female patients with inherited bleeding disorders in United States Haemophilia Treatment Centres. Hemophilia: Volume 17, Issue Supplement s1 Pages 1-45.

11. Haldane, J.B.S. (1935) the rate of spontaneous mutation of a human gene. Journal of Genetics, 31, 317-326.

12. Ulla Hedner; David Ginsburg; Jeanne M. Lusher; and Katherine A2000, High, Congenital Hemorrhagic Disorders: New Insights into the Pathophysiology and Treatment of Hemophilia. American Society of Hematology; 241-65.

13. Gitschier, J.; Wood, W.I.; Goralka, T.M.; Wion, K.L.; Chen, E.Y.; Eaton, D.H.; Vehar, G.A.; Capon, D.J.; Lawn, R.M. Characterization of the human factor VIII gene. Nature 1984, 312, 326-330.

14. Bagnall, R.D.; N. Waseem; P.M. Green; F. Giannelli,. (2002). recurrent inversion breaking intron 1 of the factor VIII gene is a frequent cause of severe hemophilia A. Blood 99 (1):168-174.

15. Lakich, D. ; Kazazian, H. H. Jr. ; Antonarakis, S. E. ; Gitschier, J. (1993) .Inversions disrupting the factor VIII gene are a common cause of severe haemophilia A . Nature Genetics; 5(3): 236 - 41.

16. Rossiter, J.P.; Young, M.; Kimberland, M.L.; Hutter, P.; Ketterling, R.P.; Gitschier, J.; Horst, J.; Morris, M.A.; Schaid, D.J.; de Moerloose, P.(1994). Factor VIII gene inversions causing severe hemophilia A originate almost exclusively in male germ cells. Hum. Mol. Genet., 3, 1035-1039.

17. Bagnall, R.D.; F. Giannelli and P.M. Green. (2005). Polymorphism and hemophilia A causing inversions in distal Xq28: a complex picture. J Thromb Haemost 3 (11):2598-2599.

18. Bagnall, R.D.; F. Giannelli; P.M. Green (2006): Int22h-related inversions causing hemophilia A: a novel insight into their origin and a new more discriminant PCR test for their detection. J Thromb Haemost 4 (3):591-598.

19. Antonarakis, S.E.; Rossiter, J.P.; Young, M.; Horst, J.; de Moerloose, P.; Sommer, S.S., et al. (1995). Factor VIII gene inversions in severe haemophilia A: results of an international consortium study. Blood; 86:2206-12.

20. DE Brasi, C.D. and D.J. Bowen (2008). Molecular characteristics of the intron 22 homologs of the coagulation factor VIII gene: an update. J Thromb Haemost 6 (10):1822-1824.

21. Miguel Martín Abelleyro, Liliana Carmen Rossetti, Claudia Pamela Radic, Miguel Candela, Irene Beatriz Larripa, Carlos Daniel De Brasi. (2012). Are 
int22h-mediated deletions a common cause of hemophilia? Annals of Hematology, Volume 91, Issue 4, pp 633-636.

22. Youssoufian, H. ; Kazazian, H.H, Phillips, D.G.; Aronis, S.; Tsiftis, G.; Brown, V.A. ; Antonarakis, S.E. (1986). Recurrent mutations in hemophilia $A$ give evidence for $\mathrm{CpG}$ mutation hotspots. Nature; 324(6095):380-2.

23. Levinson, B.; Kenwrick, S.; Lakich, D.; Hammonds, G. Jr.; Gitschier, J. (1990). A transcribed gene in an intron of the human factor VIII gene .Genomics; $7(1): 1-11$.

24. Levinson, B.; Kenwrick, S.; Gamel, P.; Fisher, K.; Gitschier, J. (1992). Evidencefor a third transcript from the human factor VIII gene .Genomics; 14(3): $585-9$.

25. Freije, D.; Schlessinger, D. A .(1992). 1.6-Mb contig of yeast artificial chromosomes around the human factor VIII gene reveals three regions homologous to probes for the DXS115 locus and two for the DXYS64 locus. Am. J. Hum. Genet. 51, 66-80.

26. Peters, M.F.; Ross, C.A. (2001). Isolation of a 40 kDa Huntingtin - associated protein. J. Biol. Chem., 276, 3188-3194.

27. Frazer, K.A.; Murray, S.S.; Schork, N.J.; Topol, E.J. (2009). Human genetic variation and its contribution to complex traits. Nat Rev Genet; 10: 241-51.

28. Naylor, J.; Brinke, A.; Hassock, S.; Green, P.M.; Giannelli, F. Characteristic mRNA abnormality found in half the patients with severe haemophilia $A$ is due to large DNA inversions. Hum. Mol. Genet. 1993, 2, 1773-1778.

29. Preethi, S. N.; Shrimati, D. S.; Chandrakala, S.; Kanjaksha, G. (2014). Mutations in Intron 1 and Intron 22 Inversion Negative Haemophilia A Patients from Western India. Plos One: 9 (5): 1-9. e97337.

30. Mantilla Capacho J.M. Beltrán-Miranda C.P., LunaZáizar H., Aguilar-López L., Esparza-Flores M.A., López-Guido B., Troyo-Sanromán R., Jaloma-Cruz A.R. (2007). Frequency of intron 1 and 22 inversions of Factor VIII gene in Mexican patients with severe hemophilia A. American Journal of Hematology. 82(4):283-7.

31. J. Becker, R. Schwaab, A. Möller-Taube, U. Schwaab, W. Schmidt, H. H. Brackmann, T. Grimm, K. Olek, and J. Oldenburg. (1996). Characterization of the factor VIII defect in 147 patients with sporadic hemophilia $A$ : family studies indicate a mutation type-dependent sex ratio of mutation frequencies. Am J Hum Genet; 58(4): 657-670.

32. Naylor, J.A.; Green, P.M.; Rizza, C.R.; Giannelli, F. (1992) Factor VIII gene explains all cases of haemophilia A. Lancet, 340, 1066-1067.

33. Martín-Salces $M$, Venceslá $A$, Alvárez-Román MT, Rivas I, Fernandez I, Butta N, Baena M, FuentesPrior P, Tizzano EF, Jiménez-Yuste V. (2010). Clinical and genetic findings in five female patients with haemophilia $A$ : Identification of a novel missense mutation, p. Phe2127Ser. Thromb Haemost.; 104 (4): 718-23.

34. Mannucci, P. M.; Tuddenham, E. G. D. (2001). The hemophilias from royal genes to gene therapy. The New England Journal of Medicine; 344, No. 23:1773-1779.

35. Ludlam, C.A.; Pasi, K.J.; Bolton-Maggs, P.; Collins, P.W.; Cumming, A.M.; Dolan, G.; Fryer, A.; Harrington, C.; Hill, F.G.; Peake, I.R.; Perry, D.J.; Skirton, H.; Smith, M.(2005). A framework for genetic service provision for haemophilia and other inherited bleeding disorders. Hemophilia.; 11 (2): 145-63.

36. Thomas S, Herbert D, Street A, Barnes C, Boal J, Komesaroff P. Attitudes towards and beliefs about genetic testing in the hemophilia community: a qualitativestudy. Haemophilia. 2007; 13:633-41.

37. Chi, C.; Shiltagh, N.; Kingman, C.E.; Economides, D.L.; Lee, C.A.; Kadir, R.A.(2006). Identification and management of women with inherited bleeding disorders: a survey of obstetricians and gynaecologists in the United Kingdom. Hemophilia. ; 12(4):405-12.

38. Plug, I.; Mauser-Bunschoten, E.P.; Brocker-Vriends, A.H.; van Amstel, H.K.; van der Bom, J.G.; van Diemen-Homan, J.E.; Willemse, J.; Rosendaal, F.R.(2006). Bleeding in carriers of hemophilia. Blood. 108:52-6.

39. Laurie, A.D.; Hill, A.M.; Harraway, J.R.; Fellowes, A.P.; Phillipson, G.T.; Benny, P.S. ; Smith, M.P.; George, P.M. (2010). Preimplantation genetic diagnosis for hemophilia A using indirect linkage analysis and direct genotyping approaches. Journals of Thrombosis and Hemostasis; 8(4): 783-9.

40. Peake, I.R.; Lillicrap, D.P.; Boulyjenkov, V.; Briët, E.; Chan, V.; Ginter, E.K.; Kraus, E.M.; Ljung, R.; Mannucci, P.M.; Nicolaides, K. (1993). Report of a joint WHO/WFH meeting on the control of haemophilia: carrier detection and prenatal diagnosis. Blood Coagulation and Fibrinolysis; 4(2): 313-344. 